\title{
1968, O ANO QUE AINDA FAZ PENSAR: INTELECTUAIS INDAGAM SOBRE A IRRUPÇÃO DOS JOVENS NA SOCIEDADE INDUSTRIAL
}

\author{
Maria LuCia de Amorim Soares* \\ LeANDRo Petarnella**
}

Recebido em: 02 de março de 2009

Aprovado em: 29 de abril de 2009

\begin{abstract}
*Docente do Programa de Pós-Graduação Stricto Sensu em Educação da Universidade de Sorocaba. Dra. em Ciências: Geografia Humana, pela Universidade de São Paulo. E-mail: maria.soares@prof.uniso.br **Profo titular da Universidade Nove de Julho. Mestre em Educação pela Universidade de Sorocaba. Email: leandro-nunes@uol.com.br
\end{abstract}

Resumo: Tendo como referência os embates de intelectuais franceses efetivados durante duas mesas redondas realizadas em Paris, no fervor dos meses de maio/junho de 1968, a partir da pergunta: Por que os estudantes? o presente artigo busca participar da comemoração do quadragésimo aniversário da irrupção dos jovens na sociedade industrial francesa, com seu questionamento sobre a universidade enquanto forma de reprodução de um sistema opressivo e discriminatório; através da análise dos acontecimentos estudantis, busca realçar o verdadeiro cerne da questão: as conseqüências da sociedade industrial tecnocrata que cada vez mais se desenvolve dominada pelo espírito mercantil. Ao trazer à tona e debater documentos da época e depoimentos dos protagonistas identifica a força do impacto de um Movimento que se colocava na perspectiva radical com o modelo de vida, de trabalho, de produção cultural, criando sua própria maneira de decodificar, negar e renovar as relações ossificadas na escola, na família, na cultura, na ação política e econômica.

Palavras-chave: França. Maio de 1968. Movimento estudantil. Universidade. Relações ossificadas.

\section{8, THE YEAR THAT STILL MAKES YOU THINK: \\ INTELLECTUALS ASK QUESTIONS ABOUT THE YOUTH'S OUTBURST IN THE INDUSTRIAL SOCIETY}

Abstract: Having as reference the conflicting arguments of French intellectuals during two round tables in
Paris, in the heat of the may/june of 1968 disturbances, while discussing the question: "Why the
students?", the present article wishes to participate in the celebration of the fortieth anniversary
of the eruption of the youth in the French industrial society and their perception of the university
as a means of reproduction of an oppressive and discriminatory system. Through the analysis of
these events, the paper tries to bring to light the essence of the question: the consequences of the
technocratic industrial society that has increasingly been ruled by a mercantile spirit. By bringing
forth and debating documents from the period and testimonies of the protagonists, it identifies the
impact of a Movement that was based on a radical perspective according to a model of life, work,
and cultural production, creating its own way of decoding, denying and renewing the petrified
relationships inside the university, the family, in culture and in political and economical action.

Keywords: France. May of 1968. Student Movement. University. Petrified Relationships. 
A Universidade traz sua data de criação da época pré-industrial e pré-capitalista, sobrevivendo graças a uma forte unidade da instituição e da ideologia, da qual se quer preencher o atraso concebido sobre o modelo da empresa. Sua longa duração está vinculada ao lugar intermediário que ocupa como instituição marginal, enquanto as transformações da sociedade a empurram para o centro. Estas são considerações de Henri Lefebvre, em 1968, durante a revolta dos jovens na França, afirmando, com arrebatamento, que a universidade estava arriscando sua existência:

Função social, isto é, inicialmente pedagógica - centro de produção do conhecimento, de idéias e também de homens - ela se mantém enquanto suporte de uma universalidade? De que universalidade pode se tratar? Ou a universidade estoura segundo as necessidades especializadas da divisão do trabalho e do mercado em instituições separadas, autônomas, tecnizadas, com a perspectiva ótima de contribuir a uma educação permante (reciclagens). Ou ela se reconstrói segundo uma perspectiva global, levando a universidade a um nível mais elevado e mais concreto. $(1968$, p. 154)

Em mesa redonda: Por que os estudantes? realizada no dia 11 de junho de 1968, tendo entre os presentes Jean Chesneaux, Henri Lefebvre, Serge Jonas, Jacques Berquer e outros, Christiane Glucksmann situa as ideologias e as instituições universitárias dizendo: "se a crise inicialmente estourou na universidade, é que ela era o lugar de uma contradição superdeterminada que no momento era o elo mais fraco do regime" (LEFEBVRE, 1968, p. 56). Lutando contra uma dupla estrutura da universidade e contra seu caráter classista - de uma parte o sistema humanista clássico e as ideologias liberais, e de outra parte, o sistema tecnocrata que se instala com o seu ensino visando adaptar a formação e a pesquisa às necessidades da indústria e formar os quadros da produção capitalista, os estudantes colocaram uma questão global da cultura, do seu conteúdo e de sua transmissão social e pedagógica. Glucksmann acrescenta: "a relação pedagógica foi vivida, no começo da luta numa relação direta de classe. O professor era assimilado ao patrão e ao Estado (relação de autoridade) [...]" (p. 57)

Na primeira mesa redonda, realizada em 23 de maio de 1968, com a participação de Serge Jonas, Henri Lefebvre, Lucien Goldmann entre outros, Jacques Berque ao dizer que a revolução vem sempre de onde não se espera, respondendo a uma lógica subterrânea e a encadeamentos objetivos, afirma que a juventude estava se revoltando contra os "encolhedores de cabeças", intimando com base em uma solidariedade real os patrões, a sociedade em seu conjunto, intimando os trabalhadores aos exploradores, as nacionalidades humilhadas e culturas 
eludidas do mundo àquelas que ocupam o primeiro plano, numa relação profunda que engaja a todos na mais historicizante história. Para ele essa história, sustentada pela revolução tecnológica que se acelerava todos os dias mudando de caráter e quase de qualidade, com a passagem do domínio de causalidades cinéticas às da eletrônica, cada um desses estágios criando novas relações e cavando novas hipóteses traduziam a juventude no papel de intelectuais:

Os estudantes são a intelligentsia no mundo da juventude ou a juventude no papel dos intelectuais. O que é um intelectual? Essencialmente, o desestabilizador da sociedade, e particularmente nos períodos em que o impulso tecnológico e as relações que ele inova ou pertuba confere uma importância muito grande ao grupo mais capacitado à análise e aos valores de expressão. É, portanto, esse grupo que, entre todos, é o mais adequado a sentir e a fazer sentir, a analisar e exprimir as contradições, e por isso mesmo a ativar essa convertibilidade dos fatos em signos, das coisas em valores - e a recíproca - que constituem um aspecto essencial do ato de viver em sociedade. O que é juventude? É um grupo particular, mas ainda mais, é um modo da sociedade global, um e outro oscilantes em relação à história, ao menos tal como ela é feita e intespretada pelos adultos. O jovem, como a mulher, como o camponês, como o homem das culturas ocidentais, é relegado pela vulgata dominante a uma posição marginal. (LEFEBVRE, 1968, p. 13)

Insistindo nas causas próprias da revolta estudantil na França, Serge Jonas propõe em primeiro lugar a da situação do ensino superior: ensino esclerosado e anacrônico. Em seu conteúdo: matérias fragmentadas, ausência de uma visão de síntese, predominância da abstração, utilização de esquemas desvalorizados, não abertura em relação às idéias, teorias e pesquisas novas. Em sua forma: "curso magistral durante o qual os estudantes não podem nem escutar, nem fazer perguntas, nem discutir, mas devem limitar-se a transcrevê-lo como estenógrafos" (LEFEBVRE, 1968, p. 35). Mandarinato, indiferença dos professores em relação à matéria ensinada e seu papel pedagógico, toda ênfase estando colocada na carreira, nos diplomas, na preparação para o exame. Em sua organização e funcionamento: programa uniforme para todas as faculdades da França, vestígio da centralização napoleônica. Insuficiência de locais e anfiteatros superlotados.

Para Serge Jonas a segunda causa específica da França é o aumento demográfico que se seguiu à segunda guerra e que fez mais agudas a insuficiência de locais, de equipamentos e de professores em todos os graus de ensino. A terceira causa foi o inverso do que era procurado: uma superpolitização da juventude, num país que fornecia a tecnocracia e o autoritarismo em todos os níveis, com 
o desaparecimento de corpos intemediários para a tomada de decisões. Estas parecem ser algumas das principais causas do que Jean Pronteau chamou a sobredeterminação, numa conjunção de fatores mundiais e específicos. $\mathrm{Na}$ verdade, o fenômeno da quantidade é de importância primordial, diz ele:

Éramos 50.000 quando eu era estudante, são agora mais de 600.000 e há 1.200 .000 alunos nos cursos finais que marcham na mesma direção. Trata-se de um grupo muito numeroso em sua parte homogênea em relação aos que existiam em outras circustâncias históricas; esses estudantes que se preparam para ser ou que desejariam sê-lo não vão dirigir-se, a maior parte, quer queiram, quer não, para esta micropropriedade que se chama profissões liberais, seja para a posse dos meios de produção ou sua gestão no nível mais elevado, seja para os cargos do Estado.

Eles vão, na maioria, situar-se no que Marx definia como proletariado: os que estão excluídos dos meios de produção; e vão se situar, em geral, graças à evolução científica, técnica e econômica da sociedade, contra a corrente dos processos de produção... Todo esse fundo histórico começa a ser recolocado em questão... Provavelmente isso não é ainda consciente, mas me parece ser uma das novidades do movimento atual, muito visível entre os estudantes, mas já aparente nas fábricas: não substituir uma hierarquia por outra, não mudar somente a base econômica, isto é, além de uma nacionalização geral, reecontra o mesmo sistema de vida, as mesmas relações sociais e humanas. "Mudar de vida" é o que querem as pessoas, como dizem, e isso não é mudar uma equipe por outra no mesmo contexto institucional... Essa é, na minha opinião, a consequência geral do fenômeno mais recente: a revolução científica e técnica que resultou num superdesenvolvimento econômico... a contestação é geral porque a obstrução quase atingiu o limite do suportável para a juntentude, que, ela, não adquiriu ainda hábitos, reflexos, o procedimento que nos tornam tolerantes. (LEFEBVRE, 1968, p. 15-18)

Já as causas, em escala mundial, podem estar determinadas pela:

1) Contestação da sociedade de consumo pelos intelectuais e estudantes americanos e alemães, pela luta efetuada contra a guerra do Vietnam, a miséria e o racismo, por uma nova esquerda americana e os negros americanos, bem como a luta contra o imperialismo ou a ditadura pelos estudantes em diversos países do mundo;

2) Luta do terceiro mundo contra o imperialismo: a China e a revolução cultural, Cuba, o Vietnam, o socialismo árabe; 
3) Luta dos intelectuais e estudantes dos países socialistas contra a burocracia, o monolitismo, o estanilismo e o dogmatismo em matéria ideológica e cultural, luta por uma maior liberalização, uma maior participação dos cidadãos nas decisões e por um conteúdo socialista mais autêntico das relações entre os homens;

4) Movimento de reflexão de diversos marxistas italianos, ingleses e franceses da Nova Esquerda sobre as condições de revolução e de edificação do socialismo nos países desenvolvidos da Europa ocidental.

Lucien Goldmann (LEFEBVRE, 1968, p. 5-15) mostrou, na mesma reunião, que esses quatro movimentos tinham diferenças, entretanto com elementos comuns: situando-se todos os quatro fora do capitalismo ou se proporndo a combatê-lo. Em medidas diversas eles se opõem às hierarquias, à burocracia, à tecnociência, aos aparelhos e fornecem o desenvolvimento da espontaneidade e da livre discussão. Enfim, sempre em medidas diversas todos os quatro se utilizavam da revolução proletária e do marxismo.

Afimando que é cedo para fazer uma análise dos acontecimentos Henri Lefebvre formula algumas reflexões, que, apesar de longas, são carregadas de importância:

O que chama a atenção é o que, como dizia Berque, o movimento revolucionário vem de onde não se esperava. Era esperado de setores fortes da sociedade, de certos pontos fortes, por exemplo, da classe operária organizada; ele vem de um vazio, de um lugar social em que se fazia uma lacuna. Marcuse fez um quadro de uma sociedade em que tudo está cheio e em que todo aquele que procura destacar-se é imediatamente destruído ou recuperado. Houve alguma coisa, mas essa sociedade não está tão cheia quanto Marcuse a pintou, há falhas, buracos, é assim que se constitui a nova forma de contestação. Gostaria de insistir na originalidade deste termo e de seu conteúdo e no que ele traz de negativo. É pelo negativo que se introduz o positivo... Essa sociedade de capitalismo e de organização científica [gente de laboratório] apresenta novas contradições... Certamente os estudantes percebem o fato de que só tem a oferecer sua força de trabalho no mercado da produção intelectual... É uma das razões, talvez não a única de solidariedade pressentida, percebida e realizada entre estudantes e os trabalhadores. Se eles se percebem como trabalhadores, não é por metáfora... Entretanto, há a possibilidade de um poder estudantil? Creio que o movimento estudantil resulta não somente numa contestação, mas numa prática contestante, que é alguma coisa 
de bastante novo... o movimento estudantil só pode se manter visando objetivos globais. Mas quais? Que se lhe pode propor? É a reinserção da teoria na política que constitui o movimento. A palavra de ordem da autogestão é de extrema importância... propõe problemas de sociedade em seu conjunto. (LEFEBVRE, 1968, p. 18-20)

Henri Lefebvre se interroga somente, e propõe mais hipóteses do que respostas ao dizer que toda a teoria desse movimento deve ser feita com muita prudência, ser modificada à medida dos acontecimentos, segundo a prática evolua numa direção ou na outra. Como Jacques Berque analisa a repressão classificatória própria à sociedade que está proposta para ser destruída, Lucien Goldmann encara a mutação de mentalidade que está ocorrendo. Já Jean Pronteau usa de lirismo: "mudar de vida", como reclamava o poeta Rimbaud, quanto "transformar o mundo" de Marx, mas com uma exigência primeira da felicidade. "A Felicidade é uma idéia nova nas escolas de Ciência Política", dizia um grafite parisiense.

Jean-Pierre Peter rompe a rigidez das colocações construindo um pensamento que trata das forças de resistência, ainda quietas no seu canto, para melhor deixar se perder a força nova que as ameaça:

Ela atacará um dia. Ela não deixará seu tempo ao movimento. Acontece que este já tem um sucesso no seu plano moral e político, que gerações de nossos ancestrais não tinham obtido: fazer aparecer a mentira, a trapaça dessa ordem social nova e apaziguante que nos é preparada; fazer sentir a espíritos sempre mais numerosos à natureza política de toda situação, de toda ação, de todo contexto de vida, de todas relações materiais e humanas, a natureza política, não neutra, do saber, quer seja recebido, quer seja transmitido,.... se a esperança é desapontada, se as coisas devem levar para outro lugar que não o ponto que se espera, não vão nos dizer, um dia talvez próximo: Então, essa revolução, vocês a estão traindo.... Já posso ver alguns de nossos mestres de esquerda acusar aqueles de nós que querem seguir seu caminho... aceitem reformas transitórias, assegurem suas retaguardas". Talvez... Mas nosso projeto está em outro lugar. As reformas aceitáveis no momento não nos interessam: elas nos desmentiriam. Devemos abalar ainda mais o edifício social e o regime para que a Universidade esteja prestes a se reformar além da boca para fora, para que não se instaurem poderes ainda mais insuportáveis.... esse movimento, assim como a varíola, é pontuado por um contágio inverossímil que aterroriza os poderes: ... é nisso que o presente movimento é importante, é porque ele coloca a clivagem não mais entre as classes sociais, mas entre aqueles que têm o poder e aqueles que o sofrem. (LEFEBVRE, 1968, p. 20-25) 
Normalmente as mass-media são consideradas integradoras afirma Fréderic Bon. Entretanto, a grande imprensa, o rádio e a televisão que nivelariam por baixo a mentalidade política, apagando as oposições e sendo responsáveis pela "despolitização" realizavam um papel diferente. Diz Bon:

Os mecanismos do sistema de informação voltaram-se contra seus autores. O gosto pelo sensacional, pelo sangue, que desvia habitualmente o leitor, o ouvinte ou o espectador da política tornou-se em Maio um fator de mobilização.... Para chegar ao controle do ciclo econômico, para manter um certo nível de expansão, o capitalismo precisa de duas coisas: de um lado, reforçar a organização social, de outro, assegurar uma inovação técnica permanente.... O neo-capitalismo engendra assim uma sociedade hierárquica permanente... Aí se encontra, creio, a origem da crise atual dos processos de socialização: o sistema de ensino e a família.... O drama coletivo que se desenvolve de modo espetacular no Quartier Latin foi procedido, sem dúvida, por milhares de dramas individuais ocultos: o choque na família entre o filho e o pai. (LEFEBVRE, 1968, p. 30)

\section{A única maneira de aprender é questionando}

A civilização européia, no fim do século XIX era quase que essencialmente segregada e consumida pelo homem, adulto, burguês, europeu. As mulheres, os jovens, os proletários e os não europeus estavam marginalizados em relação à civilização. Fundada sobre a tradição judaica-cristã e formas intelectuais e estéticas greco-latinas era o produto de uma sociedade agrícola, artesanal e mercantil, baseada na família patriarcal e organizada de uma forma clerical, militar ou monárquica. Sua expansão deveu-se à conquista e colonização de outros povos e à destruição de suas culturas essencialmente pela aristocracia e pela burguesia nacional. Em maio de 1968, era um quarto feminino, um quarto juvenil, um quarto popular e um quarto não europeu segundo Serge Jonas, sendo que os estudantes, melhor que os outros, estavam bem colocados para tomar consciência da contradição que existia entre um ensino ultrapassado, enquanto os pensamentos de Marx, Freud e de Einstein, e o conjunto das descobertas nas ciências exatas e humanas transformavam os quadros mentais e os sistemas de referência; a automação, a energia nuclear, a eletrônica e a navegação aérea e espacial transformavam os meios de produção de organização, de informação e de comunicação. Ainda, segundo Serge Jonas (1968, p. 19):

Não se trata somente de tratores no campo e na transformação da classe camponesa, nem da organização do território por um urbanismo 
que se pretende tal, nem de uma organização tecnocrática de produção. A que vivemos é talvez a mais importante que a humanidade conheceu desde a revolução neolítica. Está na escala planetária e equivale à soma de todos os grandes períodos de ruptura, de transição, de desordem e de revolução da História: o nascimento das cidades, a revolução metalúrgica, o nascimento das grandes religiões universais, a queda do império Romano e do Império de Han, o ano mil, a Renascença e a revolução industrial.

Mas, o meio estudantil é um meio pequeno-burguês. Daí o perguntar, com Jean Sanvoisin, por que os estudantes na Europa e na França em particular, se enfrentavam com o Estado burguês, enquanto eles aparecem como um meio relativamente privilegiado? Resposta do próprio Sanvoisin:

A resposta a essa pergunta já foi dada em 1946, na Carta da UNEF que declara: não há problemas estudantis, mas aspectos estudantis de problemas gerais.... É claro que a Universidade francesa é a aplicação do Plano Fouchet que cristalizou a revolta dos estudantes.... O Plano Fouchet visa, em suma, a excluir da Universidade dois terços dos estudantes para transferi-los seja diretamente para a produção, sem qualificação, seja para Institutos Universitários de Tecnologia que não são Faculdades; da mesma forma, esse plano Fouchet institui o vestibular, recoloca em questão os direitos e as vantagens adquiridas dos estudantes, como o IPEs, as bolsas, o direito de alojamento na cidade, etc. (LEFEVBRE, 1968, p. 43)

Henri Lefebvre, no ensaio "A irrupção: de Nanterre ao auge", tendo em vista mostrar o Movimento e contribuir com alguns elementos para uma teoria, transcreve de Engels no Prefácio do $18^{\circ}$ Brumário:

A França é o país onde as lutas de classes foram realizadas a cada vez, mais do que em qualquer outro lugar, até a decisão completa e onde, por conseguinte, as formas políticas mutantes, no interior das quais elas se movem e nas quais se resumem seus resultados, assumem contornos mais nítidos. Centro do feudalismo da Idade Média, país clássico, desde o Renascimento, da monarquia hereditária, a França, na sua grande Revolução destruiu o feudalismo e deu ao domínio da burguesia um caráter de pureza clássica que nenhum outro país alcançou na Europa. Da mesma forma, a luta do proletariado revolucionário contra a burguesia reinante reveste-se aí de formas agudas, desconhecidas em outros lugares. (Engels: Prefácio à terceira edição alemã, 1885, do $18^{\circ}$ Brumário de Luís Bonaparte). (LEFEVBRE, 1968, p. 72) 
Do ponto de vista da análise dos fenômenos urbanos, o Movimento se desdobrou em vários tempos, destacando-se de um lugar social para um outro lugar. Parte da Faculdade de Letras (e Ciências Sociais) de Nanterre deslocando-se e se estendeu para Paris, depois para o interior, não sem antes encontrar um centro no Quartier Latin, em torno da Sorbonne e dentro desse lugar ser consagrado.

Nanterre. Faculdade parisiense fora de Paris, não longe do Ministério da Defesa, lugar de edifícios comerciais, transportadores rodoviários, de vizinhança das favelas, de escavações para construção do metrô-expresso, de moradias baratas e empresas industriais, lugar marcado, tópico e típico, que se apresentava como um vazio, lugar de paisagem desolada. As construções concebidas conforme as categorias mentais de produção e da produtividade industriais da sociedade neo-capitalista estavam destinadas à produção de intelectuais medianamente qualificados e de "pequenos quadros" (Lefebvre). Em Nanterre "a felicidade assume uma forma" diz uma inscrição nos muros.

Os edifícios da Faculdade, especializados para a função do ensino - imensos anfiteatros ou pequenas salas funcionais, hall cinzento e torre de administração se tornam o lugar da reunião pública. Já a função de habitar mantém as tradicionais separações entre moças e rapazes, numa espécie de internato com regulamento vetusto, entre trabalho, lazer e vida privada. A Cidade (Paris) torna-se o lugar das aspirações e das rebeliões sexuais enquanto Nanterre é a segregação duplamente imposta: funcional e social, industrial e urbana.

As moças e rapazes provenientes dos bairros abastados de Paris representavam a revolta contra os Pais, o conflito das gerações, numa crise de autoridade que é apenas a aparência de uma crise mais profunda que vai da vida cotidiana às instituições e ao Estado que sustenta o conjunto. Quanto aos estudantes de origem dita modesta, muitos se orientavam segundo preocupações positivas: cursos, exames, mercado de trabalho. A colisão dessas correntes - burguesia, classe média e pequena burguesia, proletariado, contra um mesmo inimigo criou um movimento original: marginalidade social contra centralismo, anomias contra normas, contestação contra decisão, estudantes na ponta do combate político, na vanguarda, baseados nas premissas: liberdade de palavra, politização em profundidade, formação de líderes de um novo tipo. Em suma, foi um Movimento "puro", quase de completa mobilidade, desencadeando uma revolução cultural não sendo cultural, sem chefes, mas com porta vozes. Sem estrutura fixa sua efervescência preencheu o vazio dos lugares universitários.

A chegada dos estudantes de Nanterre no Quartier Latin marcou a politização do Movimento que passou a oscilar entre a alegria urbana e a violência, entre as brincadeiras e a guerrilha urbana. Transgressão e criação como o uso 
das máscaras Nô, brancas e sangrentas, em torno de um manequim enforcado em seu suporte, como a feitura de cartazes e inscrições nos muros parisienses. $\mathrm{Na}$ velha Sorbonne flutuavam bandeiras vermelhas e negras, a palavra se manifestando como primeira liberdade nos anfiteatros abarrotados, no pátio, na praça, no vasto fórum.

Depois desse auge o Movimento reflui. Pensa-se em subtrair do Estado setores chaves, notadamente o conjunto da Educação nacional, da formação pedagógica e ideológica numa nova esfera social, política, cultural: a sociedade urbana. Segundo Lefevbre é no desenvolvimento desigual da sociedade, em cima das contradições antigas e novas, que três camadas de superestruturas (instituições, ideologias) se sobrepõem, não sem interações:

a) Superestruturas datando da época pré-capitalista, quando predominavam ainda a produção agrícola e a vida rural, com suas imagens e representações do mundo.

b) Superestruturas datando da industrialização nos quadros sociais determinados pela burguesia, o capitalismo, a propriedade privada dos meios de produção (lembrando que a base técnica de industrialização não para de se transformar: automação, informática)

c) Superestruturas incertas, ainda mal definidas, incitadas pela transformação da sociedade que se opera nos quadros já definhantes (em outras palavras: os quadros da sociedade de consumo, do capitalismo de organização ou capitalismo monopolístico ligado ao Estado). Essa transformação em profundidade se define como sociedade urbana em gestação que emerge com sua problemática e suas exigências. $(1968$, p. 147)

Carlos Fuentes, que escreveu no calor dessa época, cujas questões continuam tão marcantes quanto atuais, informa sobre as condições concretas existentes na Universidade em 1968:

Dizem que vivemos na sociedade da abundância, mas na universidade só existe abundância de alunos e carência do restante. Em 1945, havia cerca de 120 mil estudantes nas universidades francesas; hoje a soma se eleva a mais de meio milhão, e só na Sorbonne há 160 mil. Não cabemos nas salas, e precisamos escutar as aulas nos corredores, através de um sistema de amplificação de voz. Mais de 30 mil estudantes querem utilizar a biblioteca, mas só há capacidade para quinhentos leitores. Nós nos vemos obrigados a ler e a preparar aulas nos cafés, nos jardins públicos (quando o tempo permite) ou nos quartos dos empregados domésticos que nos alugam no Bairro Latino por 250 francos mensais. Nessas circunstâncias, perdemos o contato com os 
professores. Quase todos se limitam a ditar a mesma disciplina há trinta anos, sem que o aluno tenha a menor possibilidade de contestar esse ensino quase periclitante, raramente revisado ou atualizado.... a maioria não lê livros, somente as anotações mimeografadas para passar nos exames de final de ano. O objetivo da universidade atual é memorizar uma cultura morta dentro de um sistema de remoto paternalismo, isto é, a universidade segue a imagem do Estado burguês. (2008, p. 53)

Para remediar essa situação os estudantes sugeriram a reforma universitária numa relação nova, sem hierarquia, entre estudantes e professores; comissões mistas de professores e estudantes a fim de discutir a forma e o conteúdo do ensino; gestão paritária; provas de controle em vez de exames; formar profissionais para servir à burguesia; construir aprendizagem questionando. Em suma, em um nível imediato; desejavam a reforma universitária, para deixar de ser súditos transformando-se em cidadãos, e assim poder atuar como adultos, numa relação autêntica entre os estudos e a futura atuação profissional.

Um cartaz da Sorbonne proclamava: "A revolução que vai colocar em dúvida não só a sociedade capitalista, mas também a sociedade industrial. A sociedade do consumo deve morrer uma morte violenta. A sociedade alienada deve desaparecer da história. Estamos inventando um mundo novo e original. A imaginação tomou o poder”. A imaginação tomou o poder com paralelepípedos e com palavras. O pavé, o belo e humilde paralelepípedo das ruas de Paris, adquiriu uma gama fetichista: foi a primeira arma de contra-ataque dos estudantes contra a polícia, meio de comunicação de massa, foi a maneira de se fazer escutar em uma sociedade onde os mass media foi monopolizado pela burguesia. Mensagem imprescindível anunciando que "Debaixo dos paralelepípedos estão as praias."

É no bojo de todos estes acontecimentos que se ergueram barricadas, símbolo revolucionário, barricadas de árvores, bancos, grades, carros, paralelepípedos. Por trás delas, toda uma vida se desenvolveu em discussões com pessoas do bairro que apoiavam os estudantes. "A barricada fecha a rua mas abre o caminho", lia-se numa inscrição dando um dos sentidos da festa nas barricadas, num estado de felicidade permanente.

O Maio francês significou uma crise de autoridade generalizada. Se em 1968 a velha sociedade não morreu, ou melhor, se a nova não chegou a nascer, ela não deixa de ser uma grande e generosa explosão revolucionária. Jacques Baynac chega mesmo a dizer que, se não se tomou o Poder, foi porque a noite das barricadas deixou de ser dominante: "ela foi aos poucos sendo submergida 
pela estratégia tradicional das revoluções do capital, estratégias de conquista de território, da conquista do Poder [...]" (apud MATOS, 1981, p. 95). A juventude parisiense representou a insatisfação com a ordem conservadora, capitalista e consumidora, numa explosão de espontaneidade, sua virtude e ao mesmo tempo seu defeito.

A revolução nasceu em Nanterre, conglomerado cinzento de blocos de cimento, para conter a superlotação estudantil da Sorbonne. Praticando uma espontaneidade consciente e criadora, criticando o mundo burocratizado e desencantado, colocou como lema a verdade triunfante do desejo: 68 foi uma luta para a vida, por um planeta mais azul (slogan do Movimento), através de uma ação antimídia - "é proibido proibir, Lei de 10 de maio de 1968", grafite que contestava inscrições oficiais que diziam "É proibido colocar cartazes, lei de 29 de julho de 1881 ". O ato criador foi a ocupação, a profanação, a dessacralização da Sorbonne que se espalhou pelas universidades das províncias a setores inteiros da intelligentzia, pesquisa científica, rádio e televisão, cinema e escritores.

$\mathrm{O}$ ato de ocupar a universidade constituiu uma audácia inédita no mundo da intelligentzia porque os estudantes se recusaram a se tornarem, conforme elenca Olgária Matos (1981, p. 72):

- professores a serviço da seleção no ensino, de que os filhos da classe operária são as vítimas,

- sociólogos fabricantes de slogans para as campanhas eleitorais governamentais,

- psicólogos encarregados de fazer "funcionar" as "equipes" de trabalhadores "segundo os melhores interesses dos patrões",

- cientistas cujo trabalho de pesquisa será utilizado segundo os interesses exclusivos da economia do lucro. Nós recusamos os cursos que nos ensinaram a nos tornar isso. Recusamos os exames e os títulos que recompensam os que aceitam entrar no sistema. Nós nos recusamos a melhorar a universidade burguesa. Nós queremos transformá-la radicalmente a fim de que de agora em diante ela forme intelectuais que lutem ao lado dos trabalhadores e não contra eles.

Um panfleto parisiense de 68 dizia:

Como os trabalhadores, os intelectuais constituem um grupo social oprimido: eis porque uns e outros se encontraram unidos na luta. 
Frequentemente se coloca a questão: por que os estudantes que são privilegiados, filhos da burguesia se revoltam com tal violência? Esta questão, ao mesmo tempo em que silencia o fato de que muitos estudantes são obrigados a trabalhar para prosseguir os estudos, recobre um erro fundamental: a idéia que só a miséria material justifica a revolta e de que um que tem tudo de que precisa (no plano material) deve se encontrar igualmente satisfeito no plano moral. Na sociedade atual, o intelectual é por essência insatisfeito.... E no grafite se encontra a crítica a toda alienação, material e moral: ... (Viver sem horas mortas, gozar sem entraves). (MATOS, 1981, p. 38)

Aproveitando-se de inúmeros impasses vividos pelo Movimento, o presidente De Gaulle viajava em 29 de maio de 1968 até as bases militares francesas, na Alemanha Ocidental, para obter apoio dos generais que combateram na Argélia. Na volta faz um duro pronunciamento anunciando a dissolução da assembleia nacional e a convocação de novas eleições. No mesmo dia uma manifestação de cerca de um milhão de pessoas, chamada "maioria silenciosa", marchou em apoio ao presidente e contra a greve geral. As eleições representaram a sobrevivência do velho e não a expressão do novo. Os eleitores jovens, aproximadamente meio milhão, foram excluídos do processo eleitoral visto o Ministério do Interior ter decidido que, dada a urgência com que se convocaram as eleições, não haver tempo de regularizar essa situação.

Não deixa de ser irônico que, em última análise, quem provocou as eleições não tenha podido participar delas, reflete Carlos Fuentes. Resposta: "Que importa? Eu já votei nas barricadas pelo socialismo revolucionário. Minha cédula foi um paralelepípedo". (2008, p. 72). Numa das paredes da Sorbonne estava escrito: a primeira revolução foi política (a das nacionalidades), a segunda foi a econômica (a dos proletários) a nossa será cultural. Assim foi maio de 68 em Paris. 


\section{Referências}

FUENTES, Carlos. Em 68: Paris, Praga e México. Rio de Janeiro: Roco, 2008 .

JONAS, Serge. A irrupção: a revolta dos jovens na sociedade industrial: causas e efeitos. In: LEFEVBRE, Henri. A irrupção: a revolta dos jovens na sociedade industrial: causas e efeitos. São Paulo: Editora Documentos, 1968. LEFEVBRE, Henri. A irrupção: a revolta dos jovens na sociedade industrial: causas e efeitos. São Paulo: Editora Documentos, 1968.

MATOS, Olgaria. C. F. Paris 1968: as barricadas do desejo. São Paulo: Brasiliense, 1981. 